\title{
Política Provincial na Formação da Monarquia Constitucional Brasileira. Rio de Janeiro, 1820-1850'
}

Provincial Politics in the Formation

of the Brazilian Constitutional

Monarchy. Rio de Janeiro, 1820-1850

\section{Maria de Fátima Silva Gouvêa}

Professora no Departamento de História da Universidade Federal Fluminense
Este estudo foi desenvolvido com o apoio financeiro do CNPq - Conselho Nacional de Desenvolvimento Científico e Tecnológico e da Universidade de Londres. Uma primeira versão do artigo foi apresentada no Seminário Internacional Brasil de um Império a outro (1750-1850), São Paulo, Depto. de História/USP 05 a 09/setembro/2005.

\section{Resumo}

0 artigo considera a monarquia constitucional no Brasil da primeira metade do século XIX sob o ponto de vista da dinâmica política provincial. Analisando o caso do Rio de Janeiro, o estudo mostra a forma como a Assembléia Legislativa Provincial fluminense operou enquanto importante espaço de friç̧ão e acomodação dos múltiplos interesses que se movimentavam naquele cenário político regional. Essa instituição foi capaz de viabilizar um surpreendente grau de estabilidade política em meio a um periodo de profunda indefinição e construção de novos arranjos político-administrativos no novo país.

\section{Abstract \\ The article focuses on the Brazilian constitutional monarchy during the first half of the Nineteenth century from the provincial political dynamics point of view. By looking into the case of Rio de Janeiro, the study shows the way in which the fluminense Legislative Provincial Assembly worked as an important space for friction and accommodation among the multiple interests that moved themselves across the regional political scenery. This institution was able to provide an astonishing degree of political stability amidst a period of profound political uncertainty and the building up of new political and administrative projects for the new country.}

\section{Palavras-chave}

Império do Brasil, monarquia, constituição, debates parlamentares, poder legislativo, Rio de Janeiro

\section{Keywords}

Brazilian Empire, monarchy, constitution, parliamentary debates, legislative power, Rio de Janeiro 
0 estabelecimento da província como nova unidade político-administrativa foi certamente uma das maiores inovações introduzidas pelo novo arranjo governativo configurado pelo Império do Brasil. Surgiu então o novo elo institucional capaz de interligar formalmente o centro político-administrativo às diversas esferas locais que juntos iam compondo pouco a pouco o novo Estado.

A historiografia que tem estudado o império do Brasil tem repetidamente afirmado o caráter profundamente centralizado da monarquia constitucional brasileira. Entretanto, se por um lado, vários foram os elementos que restringiram, em meio ao Regresso, a autonomia regional e local em todo o pais, por outro, a teia de interesses e de instituições regionais que articularam a trama política e administrativa era bastante ampla e complexa.

A política imperial foi por certo algo muito mais complexo e sofisticado do que o simples favoritismo e clientelismo geridos a partir da cidade do Rio de Janeiro. Nesse sentido, uma significativa descontinuidade em relação ao periodo colonial é aqui enfatizada na medida em que haviam se constituído espaços importantes de representação dos interesses regionais/ provinciais, o que no periodo colonial havia se restringido ao âmbito das célebres câmaras. As assembléias provinciais viabilizaram parte importante das mediações que conformaram esse novo arranjo político. 0 estudo da assembléia provincial do Rio de Janeiro esclarece de modo privilegiado a natureza desse contexto.

Nesse sentido, esse estudo procura contribuir em prol de uma nova abordagem acerca da dinâmica política que deu vida à monarquia brasileira no século XIX. A província do Rio de Janeiro é aqui analisada com o objetivo de se perceber a forma e a natureza da dinâmica política que relacionou os vários diferentes grupos de interesse existentes no interior de uma dada província no império do Brasil. Sua proximidade geográfica para com a corte da monarquia colocava a província fluminense em uma posição deveras privilegiada em relação à política brasileira como um todo naquele período. Período esse que testemunhou o surgimento, o apogeu e o declínio dessa província em termos de sua preeminência política e econômica no Brasil do século XIX. Internamente, a província do Rio de Janeiro é particularmente interessante na medida em que sua economia se baseava na agricultura do café, do açúcar e de gêneros de abastecimento, fornecendo assim produtos que iam tanto para o mercado de exportação, quanto para o mercado de abastecimento interno.

A análise aqui desenvolvida procura verificar o papel das conexões que interligaram os diferentes grupos espalhados no interior da província, tanto em relação ao governo provincial, quanto à sede do governo imperial instalado na corte do Rio. Percebe-se desse modo a importância da assembléia provincial em promover, alimentar, dar sentido e movimento a essas conexões na medida em que ela servia de suporte e espaço de expressão dos interesses e dos desejos desses grupos em relação aos governos provincial e imperial. Se formalmente as regras jurídico-institucionais limitavam de modo bastante significativo o raio da ação executiva da assembléia provincial - fortemente submetida às jurisdições do presidente de provincia, conforme analisado adiante -, por outro, várias foram as estratégias acionadas pelos deputados provinciais no sentido de transformar essa mesma assembléia em um poderoso espaço de expressão e de negociação política entre os diversos grupos de interesse existentes no interior da província, 
2

GOUVÊA, Maria de Fátima S. 0 império das provincias. Rio de Janeiro, 1822-1889. Rio de Janeiro: Civilização Brasileira/FAPERJ, 2008. A propósito, ver também os instigantes estudos de Miriam Dolhnikoff, publicado em 2005 pela Editora Globo, intitulado 0 pacto imperial. Origens do federalismo no Brasil, e de Andréa Slemian, Sob o império das leis: constituição e unidade nacional na formação do Brasil (1822-1834), Tese (Doutorado em História Social). Faculdade de Filosofia, Letras e Ciências Humanas, Universidade de São Paulo, 2006.

\section{3}

GOUVÊA, Maria de Fátima S. 0 Senado da Câmara do Rio de Janeiro no Contexto das Cerimônias de Aclamação de D. João VI. Anais do Seminário Internacional D. João VI. Um Rei Aclamado na América. Rio de Janeiro: Museu Histórico Nacional, 2000. p.246-259.

\section{4}

Para uma análise das mudanças operadas na organização administrativa e institucional na região do Rio de Janeiro nesse período, tempo caracterizado por uma espécie de revolução administrativa, ver GOUVÊA, Maria de Fátima S. Dos Poderes do Rio de Janeiro Joanino: Administração e Governabilidade no Contexto do Império Luso-Brasileiro (1808-1821). In: JANCSÓ, István (org.). Independência: história e historiografia. São Paulo: Hucitec/FAPESP, 2005. p.707-752. Ver também o imprescindivel estudo de SCHULTZ, Kirsten. Versalhes tropical: império, monarquia e a corte portuguesa no Rio, 1808-1821. Rio de Janeiro: Civilização Brasileira, 2008.

5

GOUVÊA, Maria de Fátima S. Provincias. In: VAINFAS, Ronaldo (org.). Dicionário do Brasil imperial (1822-1889). Rio de Janeiro: Objetiva, 2002. p.597-599. bem como entre esses, o governo provincial e o governo imperial sediado na corte do Rio de Janeiro.

0 presente estudo analisa dois aspectos em particular. De um lado, procura situar os principais aspectos que relativizam o peso de uma corrente historiográfica, que tem enfatizado o caráter fortemente centralizado do sistema político imperial brasileiro. Esse estudo destaca a extraordinária importância dos espaços políticos intermédios - regionais - e locais na dinâmica cotidiana da vida política do império das províncias ${ }^{2}$. De outro, considera a trama política vivenciada no interior da província do Rio de Janeiro e a interação desta com a política do Brasil imperial na primeira metade do século XIX.

\section{0 império e as províncias na primeira metade do século XIX}

0 início do século XIX foi profundamente marcado pela ocorrência de mudanças na forma como o Brasil se encontrava politicamente organizado. 0 ano de 1808 assistiu a transferência da corte portuguesa para o Rio de Janeiro. Pouco tempo depois, o Estado do Brasil teve seu estatuto jurídicoinstitucional alterado para o de Reino Unido a Portugal e Algarves, bem como D. João VI era aclamado rei de Portugal na cidade do Rio de Janeiro ${ }^{3}$. Em menos de duas décadas, o centro-sul do Brasil havia vivenciado experiências extraordinárias ${ }^{4}$, processo esse que acabou por incidir em sua emancipação política frente ao império português em 1822. Vale lembrar também que, entre 1808 e 1821, as palavras capitania e província eram usadas de forma alternada e ambivalente na legislação editada pela coroa portuguesa, sendo ambos os termos utilizados na designação das unidades territoriais que integravam o império luso na América. É possível afirmar que as provincias do Brasil oitocentista deram de certo modo continuidade às unidades territoriais intermédias que constituiram a antiga administração colonial da América portuguesa - as capitanias hereditárias abolidas por Pombal em 1759 e posteriormente transformadas em capitanias régias ${ }^{5}$. Entretanto, sua maior força reside justamente na descontinuidade institucional que tais unidades suscitaram na organização político-administrativa que pouco a pouco foi sendo criada e implantada no Brasil imperial.

Nesse sentido, cabe destacar a novidade estabelecida pelo alvará de 10 de setembro de 1811 que determinou a criação de juntas eleitas regionalmente no âmbito das capitanias para auxiliar a ação governativa da Mesa do Desembargo do Paço, situada no Rio de Janeiro. Órgão esse que havia sido criado em substituição ao posto de vice-rei do Brasil em 1808. Entretanto, foi o decreto de 01 de outubro de 1821 aquele que estabeleceu a "forma da administração política e militar das provincias do Brasil" através do estabelecimento de juntas provisórias de governo via o voto dos "eleitores de paróquia de província". A lei de 16 de fevereiro de 1822 estabeleceu também a criação do conselho de "Procuradores-Gerais das Províncias do Brasil", com precedências de Conselho de Estado.

Vale ressaltar ainda a importância dedicada ao estabelecimento de novas instituições regionais de governo em meio a grave crise políticoinstitucional observada por ocasião da emancipação política, estratégia que procurou minimizar os riscos de uma possível ruptura ou fragmentação territorial. Abria-se assim espaço para o surgimento incipiente de uma representatividade política das províncias no interior do novo império em processo de formação. 
SLEMIAN, Andréa. Sob o império das leis: constituição e unidade nacional na formação do Brasil (1822-1834), Tese (Doutorado em História Social). Faculdade de Filosofia, Letras e Ciências Humanas, Universidade de São Paulo, 2006. cap.1.
Não seria por acaso que o decreto de 18 de setembro de 1822 criou o escudo de armas do Brasil com o cuidado de definir dezenove estrelas de prata no firmamento azul, simbolizando o conjunto territorial composto pelas províncias do novo país. Dois outros decretos, ambos de 20 de outubro de 1823, introduziram posteriormente alterações na forma como o governo nas províncias se encontrava organizado. 0 primeiro aboliu o Conselho de Procuradores Gerais das Províncias e as juntas provisórias de governo provincial. 0 segundo deu forma aos governos provinciais, criando o cargo de presidente de provincia e os conselhos gerais de província. Já ficava assim patenteado o papel central a ser exercido pela corte imperial na gestão administrativa provincial do pais, fato esse confirmado pela carta constitucional de 1824 no que se referia a jurisdição do imperador em relação à nomeação dos presidentes de província, bem como a fixação do período de funcionamento dos conselhos provinciais em apenas dois meses por ano6.

A Carta Constitucional de 1824 estabelecia ainda que seriam os "eleitores de província" os responsáveis por proceder às eleições indiretas de todo os cargos eletivos na nova monarquia constitucional brasileira, regra que permaneceu inalterada durante todo o periodo imperial. Situação essa que - a despeito do caráter restritivo e elitista da cidadania instituída pelo regime monárquico - possibilita destacar o papel fundamental desempenhado pelas províncias imperiais no âmbito da nova organização política do Brasil, particularmente sob o ponto de vista da representatividade e da participação política dos cidadãos no novo sistema de governo constitucionalista então instituído.

0 Ato Adicional de 1834 transformou os Conselhos Gerais das Províncias em Assembléia Provinciais Legislativas, tendo ainda ampliando o número de representantes provinciais reunidos no âmbito do legislativo provincial. Ficou assim determinado o número de representantes provinciais que se reuniram em cada uma das províncias, a saber: 36 representantes nas províncias de Pernambuco, Bahia, Rio de Janeiro, Minas Gerais e São Paulo; 28 nas do Pará, Maranhão, Ceará, Paraíba, Alagoas e Rio Grande do Sul, e finalmente, 20 representantes nas demais provinciais do Brasil. Apesar de ter sido celebrizado por seu caráter liberal e descentralizador - na medida em que permitia a nomeação de oficiais da fazenda e da justiça pelas autoridades provinciais -, 0 ato manteve inalterado o processo altamente centralizado através do qual era procedida a nomeação dos presidentes provinciais. Era ele um dos principais elementos a concorrer em prol da instituição de mecanismos de poder centralizados a partir da sede imperial da monarquia. A Lei de Interpretação do Ato Adicional, aprovada em 1837, veio enfim suprimir a relativa autonomia estabelecida pela legislação de 1834, na medida em que retirou a capacidade de nomeação dos oficiais de justiça e fazenda do âmbito dos governos provinciais.

Entretanto, os representantes locais consideravam as assembléias provinciais enquanto um importante espaço de participação e de exercício da cidadania política, como atestam as disputas em torno da validação dos diplomas que referendavam a eleição dos membros para integrar esses espaços governativos. Por maior e mais generalizada que fosse a prática de manipulação das eleições durante o periodo, a participação e a representação política constituíram mecanismos de agregação dos vários grupos ao projeto monárquico constitucionalista brasileiro ao longo do século XIX. 
GOUVÊA, Maria de Fátima S. 0 império das provincias. Rio de Janeiro, 1822-1889. Rio de Janeiro: Civilização Brasileira/FAPERJ, 2008.

BRASIL, Lei e Estatutos. Coleção de leis do Brasil desde a independência. Vol. V. Ouro Preto, 1834. p.225. Ver o artigo 10, parágrafo 6. A presidência da província também deveria informar a assembléia acerca das necessidades provinciais em relação a quaisquer mudanças nos requerimentos anuais do contingente da policia provincial. Em relação à lei do orçamento municipal, a assembléia teria que consultar as propostas encaminhadas às câmaras municipais.
A assembléia provincial do Rio de Janeiro nas décadas de 1830 e 1840

Cabe destacar primeiramente o fato de que a assembléia provincial era percebida pelos políticos fluminenses enquanto um espaço importante de expressão e vivência dos conflitos políticos experimentados entre os grupos regionais no interior da província7. É possível dividir os deputados provinciais do Rio de Janeiro em dois principais grupos. Um grupo que usufruia do apoio de forças políticas situadas fora do espaço da assembléia provincial, reunindo assim forças para garantir o trâmite da maioria de suas reivindicações. Um segundo grupo que permanecia silencioso na maioria das sessões, explicitando por vezes o fato de que não usufruia de prestigio político suficiente para expressar e defender suas posições.

É igualmente importante indicar alguns dos principais aspectos que caracterizaram o desenrolar das discussões travadas no interior da assembléia provincial fluminense. A maioria dos debates relacionava-se com a discussão e a aprovação das três leis provinciais aprovadas anualmente: a lei que definia o contingente anual da força policial da provincia e as leis do orçamento municipal e provincial, sendo essa última a mais importante de todas elas em termos de seu peso político e econômico. De acordo com o Ato Adicional de 1834, o presidente da província deveria apresentar uma proposta de lei que funcionaria como o ponto de partida desses debates 8 .

Além disso, foi possivel identificar três principais tipos de solicitações encaminhadas pelos deputados provinciais. 0 primeiro se relacionava com a insatisfação dos municípios frente ao tratamento dispensado pelo governo provincial. Geralmente, originavam-se de duas questões: o manejo das autoridades policiais a nível local durante o periodo de eleições e o tipo de apoio financeiro que os municipios recebiam do executivo provincial em termos da realização de obras públicas em suas áreas. Esses dois aspectos são reveladores do tipo de expectativa que a maior parte dos deputados provinciais tinha perante a assembléia provincial. De alguma forma, mesmo não usufruindo de apoio político externo, a maioria dos representantes entendia a assembléia provincial como um canal importante de pressão politica em favor das demandas dos municípios que representavam frente 0 governo da província.

Um segundo tipo de solicitação dizia respeito às reivindicações de funcionários da administração provincial. A maioria dos deputados frequentemente demonstrava vínculos diretos com cargos na burocracia da administração local ou provincial. Agiam eles assim como conectores a entrelaçar a assembléia à administração provincial. É interessante também notar que essa situação resultava freqüentemente em uma situação de confronto aberto entre esses deputados e aqueles mais intimamente associados ao setor agrícola. Isso se verificou de modo mais significativo a partir da década de 1860, devido às crescentes dificuldades financeiras enfrentadas pela província em termos de se manter um equilibrio entre 0 pagamento de pessoal administrativo e aquele dedicado à implementação de novas obras públicas.

Um terceiro grupo era definido pelas demandas dos deputados em relação àquilo que poderia ser definido como um setor privado. Situação que se verificava geralmente em relação à gestão de obras públicas provinciais nas diversas áreas do Rio de Janeiro, bem como em termos do cultivo de novos tipos de lavouras e do desenvolvimento de novos métodos de controle de pragas agrícolas nas grandes lavouras de exportação. Contexto esse que ganhou importância significativa durante os debates sobre 
Para maiores considerações acerca das comissões e da assembléia provincial como um todo, ver GOUVÊA, Maria de Fátima S. 0 império das províncias. Rio de Janeiro, 1822-1889. Rio de Janeiro: Civilização Brasileira/FAPERJ, 2008. propostas de construção de estradas de ferro na província. Identificam-se assim diversos tipos de alinhamentos políticos no interior da assembléia provincial, resultado dos vários tipos de associação que poderiam surgir dentre os deputados durante o desenrolar dos debates relativos a todos esses diferentes tipos de concessões.

\section{Aspectos organizacionais}

Para preparar o início dos debates, os deputados provinciais elegiam a cada ano comissões que analisavam a maior parte das propostas a discutir9. Dentre essas comissões, três deveriam preparar os já referidos projetos anuais para dar início aos debates no interior da assembléia. Outra influente comissão era a Comissão de Leis, que usufruía do poder de apresentar versão alternativa dos projetos em discussão.

Devido a várias razões, a composição dos deputados presentes na assembléia provincial fluminense mudava drasticamente de tempos em tempos. Havia duas ocasiões especiais, no entanto, nas quais os deputados tendiam a estar presentes de modo mais constante: o período de eleição das comissões e o da votação do orçamento provincial.

As comissões da assembléia desempenhavam um papel crucial em analisar inicialmente as propostas apresentadas pela presidência. As comissões também forneciam à assembléia uma importante força de trabalho, no sentido de proceder ao estudo da documentação relacionada aos projetos em discussão no legislativo fluminense.

Nesse aspecto, a comissão de Finanças era certamente a mais atarefada, já que todo o projeto que envolvesse gastos provinciais tinha que ser cuidadosamente analisado por seus membros. Além disso, a comissão tinha por incumbência analisar a proposta do orçamento provincial enviada pelo presidente da província, fazer alterações que julgasse pertinente e, em muitos casos, produzir e apresentar um projeto substituto caso a maioria dos deputados da assembléia se posicionasse contrariamente a proposta original, ocasião em que a comissão tentava estabelecer um acordo entre a presidência da província e a assembléia provincial. Argumentava-se então que isso requeria muita experiência e estratégica política por parte dos membros da comissão, o que fazia com que uma mesma pessoa permanecesse nela eleito enquanto fosse ele membro da assembléia. Experiência prévia na comissão era considerada uma importante ferramenta em favor da eleição de um determinado deputado. Em geral, um mesmo individuo tendia a ser eleito ao mesmo tempo para integrar a comissão de finanças e a comissão de projetos. Esses eram, na verdade, os mais destacados deputados da assembléia provincial, assistindo a maioria das sessões diárias e mantendo participação ativa e presença em todos os debates.

Outro ponto interessante sobre a escolha dos deputados para as comissões era que eles tendiam a ser eleitos de acordo com suas carreiras profissionais. Em sendo um padre, o deputado provavelmente seria eleito para a comissão eclesiástica. Aqueles que eram identificados como "lavradores" - mais declaradamente associados aos interesses locais - tendiam a ser eleitos para a comissão de obras públicas ou de câmaras municipais. 0 brigadeiro João Nepomuceno Castrioto foi constantemente eleito e reeleito para a comissão de força policial durante os 34 anos em que foi deputado provincial.

Em muitas ocasiões, a assembléia provincial se transformava em um verdadeiro campo de batalha entre os deputados, e entre estes e o governo 
provincial. Situação essa que variava de acordo com a época do ano e com o tipo de discussão em pauta. No entanto, um elemento de grande importância permaneceu inalterado durante todo o periodo: a luta entre interesses locais e o executivo fluminense acerca da utilização da renda provincial. Em geral os deputados agrupavam-se de maneira estratégica de modo a exercer pressão sobre a presidência provincial e o seu principal aliado na assembléia: a comissão de finanças provinciais. Mas era também verdade que o executivo provincial possuía diversas maneiras de impedir tal situação. A presidência tinha total controle sobre o período de duração das sessões anuais da assembléia provincial. 0 período regulamentar era de dois meses por ano, tempo insuficiente para que a plenária chegasse a algum acordo acerca de tão amplo leque de matérias. Era a presidência da província que tinha o poder de autorizar a convocação de sessões diárias adicionais com o intuito de que pelo menos os projetos orçamentários - municipal e provincial - fossem aprovados anualmente.

Para além desses projetos, a maioria das leis editadas pelo legislativo provincial assumiu a forma de leis de autorização. Ou seja, leis que autorizavam a presidência provincial a implementar as medidas necessárias em relação à determinada questão. A maior parte das obras públicas e das reformas administrativas foi realizada dessa maneira.

Os conflitos observados entre a presidência e a assembléia provincial concorreram para uma mútua preocupação com a "opinião pública". No caso da assembléia, isso era observado em termos da preocupação dos deputados com os jornais que noticiavam as sessões diárias. A expectativa era de que a assembléia fosse considerada uma instituição estável politicamente e preocupada com a boa gestão dos assuntos provinciais. Disputas e debates políticos muito prolongados eram entendidos como um desperdício do dinheiro dos contribuintes. É interessante notar a preocupação com a manutenção da imagem do legislativo provincial como um cenário no qual os "cidadãos civilizados" poderiam positivamente encenar o drama da política, como que demarcando uma distância para com o caos teoricamente deveria prevalecer no resto da sociedade escravocrata.

A opinião pública era particularmente utilizada por deputados fluminenses no sentido de pressionar outros deputados a comparecer a assembléia provincial de modo mais sistemático, haja vista que era bastante freqüente a ausência de quorum para realização das reuniões. Além disso, a maior parte dos jornais apoiava um ou outro grupo político nos debates que aconteciam na assembléia provincial. Eram constantes as discussões sobre artigos impressos em jornais que davam apoio às diversas facções dentro da assembléia. Deputados também se referiam freqüentemente a artigos de jornal ao discutir a maneira como a administração provincial vinha sendo gerida. Como já indicado, a mídia era um meio importante de expressão dos conflitos entre a política nacional e provincial. Ao criticar a política dos ministérios ou da presidência da província, deputados provinciais utilizavam com freqüência os informes diários acerca da assembléia, impressos no Jornal do Commercio e no Diário do Rio de Janeiro. Isso provia uma ligação chave entre sua participação na politica provincial e o resto da sociedade de maneira geral no período.

Antes de analisar alguns dos principais conteúdos presentes nos debates do período em questão, vale lembrar brevemente que o debate estava regulamentado pelos limites firmados pelo regimento interno da assembléia provincial. 0 poder da mesa da assembléia em dirigir os debates 
10

Ver a lei provincial $n^{0} 130$, de 18 de maio, em: RIO DE JANEIRO (Provincia). Presidência da ... Relatórios da ... Rio de Janeiro, 1881. (Apêndice: Quadro dos impostos e mais rendimentos das Câmaras Municipais da província do Rio de Janeiro).

Em RIO DE JANEIRO (Província). Presidência da ... Relatórios da ... Rio de Janeiro, 1881. (Apêndice: Quadro dos impostos que constituem a renda da Província do Rio de Janeiro, legislação que os regula, objeto contribuinte, sua quota atual e renda arrecadada nos exercicios de 1872 a 1880).

\section{2}

Em 1840, o artigo 5 do orçamento provincial estabeleceu que a renda provincial extraida com a exportação do açúcar deveria ser abolida. Isso permaneceu inalterada até dezembro de 1870. Ver o decreto $n \circ 214,27$ de maio de 1840 em: RIO DE JANEIRO (Provincia). Leis e estatutos. Coleção de leis da província do ... Rio de Janeiro, 1840. p. 84.

13

José Murilo de Carvalho considerou o modo como o orçamento nacional era organizado no século XIX no Brasil. Concluiu que a agricultura de exportação era responsável pela maior parte da tributação coletada no Brasil no período. Grupos vinculados ao mercado interno eram os mais favorecidos pelo sistema tributário imperial. 0 encargo mais pesado incidia sobre o comércio de escravos. Este, entretanto, era freqüentemente realizado pelas vias ilegais do contrabando. Ver CARVALHO, José Murilo de. 0 teatro das sombras. A política imperial. Rio de Janeiro: Vértice, 1988. p.31-32.

\section{4}

Para os debates durante a década de 1840 : Diário do Rio de Janeiro. Rio de Janeiro, $\mathrm{n}^{\circ} .49$ a 119,$1840 ; n^{\circ} .58$ a 72,$1841 ; n^{\circ} .48$ a101, 1842; $n^{\circ} .50$ a 124,$1843 ; n^{\circ} .7148$ a 7154,$1846 ; n^{\circ}$. 7443 a 7512,$1847 ; n^{\circ} .7762$ a 7870,1848 e no (8028 a 8120, 1849. Ver também o Jornal do Commercio, no. 59, 72, 103 e 104, 1844; \& $n^{\circ}$. 60,63 e $95,1845$.

15

Para a lista dos anos que compuseram as legislaturas da assembléia provincial do Rio de Janeiro, ver: Apêndice II in: GOUVÊA, Maria de Fátima S. O império das províncias. Rio de Janeiro, 1822-1889. Rio de Janeiro: Civilização Brasileira/FAPERJ, 2008. travados e a existência de um órgão burocrático anexo à assembléia encarregado de organizar seus papéis - a secretária da assembléia provincial -, foram algumas das características estabelecidas pelo regimento que acabou por regulamentar todo o desenvolvimento dos debates no interior da assembléia.

\section{Debates políticos}

Quando olhamos para os eventos que marcaram o cotidiano da assembléia provincial na década de 1830, três pontos devem ser destacados em particular. Em 1836, José Clemente Pereira, líder político nacional, e Joaquim Francisco Viana, representante do municipio de Campos, ambos membros da assembléia provincial fluminense, se enfrentaram fortemente na discussão do projeto apresentado por Viana acerca da reforma do sistema de sesmarias na província. Viana estava muito preocupado com a urgente necessidade de se estabelecer livre acesso às terras da província. Ele argumentou que se o acesso a terra fosse viabilizado apenas por meio da compra, a província não conseguiria atrair trabalhadores livres e nem poderia criar condições mais favoráveis ao crescimento agrícola da província.

Uma outra questão importante surgiu em 1838, quando a assembléia provincial aprovou uma lei estabelecendo que a renda da exportação do açúcar tributada em alguns municípios fluminenses deveria ser mantida nos tesouros municipais e ser usada na sua administração pública ${ }^{10}$. A lei especificava que isso se aplicava aos municípios de Campos, São Fidelís e São João da Barra. Em 1839, outra legislação estabeleceu que todo o café exportado da província fluminense era obrigado a pagar uma taxa provincial de $4 \%$ em relação ao seu valor total11. Apesar dessa mudança não ter introduzido nenhuma grande modificação na quantidade de renda coletada no período, esse movimento estabeleceu um precedente vital ao diferenciar os dois setores econômicos em particular no interior da província. Ainda mais surpreendente foi a modificação estabelecida no ano seguinte, quando o setor exportador de açúcar ficou desincumbido de contribuir para o tesouro provincial12. Essas mudanças afetaram enormemente a relação entre esses dois setores econômicos, como pode ser observado no decurso das confrontações políticas travadas dentro da assembléia provincial ${ }^{13}$.

Durante a década de 1840, os informes sobre os debates na assembléia provincial impressos no Diário do Rio de Janeiro apresentaram uma estrutura mais organizada e tenderam a retratar a maneira como os trabaIhos da assembléia se desenvolviam ${ }^{14}$. A assembléia contava ainda com a presença de políticos de projeção nacional. Aureliano de Sousa e Oliveira Coutinho, posteriormente Visconde de Sepetiba, Paulino José Soares de Sousa, depois Visconde do Uruguai, Joaquim José Rodrigues Torres, depois Visconde de Itaboraí, Eusébio de Queirós, entre outros, permaneceram como deputados provinciais fluminenses de 1835 até fins da década de 1840 . Eles também ocuparam importantes posições políticas e administrativas no sistema administrativo e político nacional. Isso fez com que a composição da assembléia fosse extremamente volátil e irregular, tornando dificil identificar grupos demarcados dentro dela. Como resultado, foi freqüente a convocação de deputados substitutos.

0 período aqui analisado foi inaugurado pela forte disputa entre três grandes propostas apresentadas durante a 3 a legislatura (1840-1841) 15. Duas delas estavam diretamente ligadas a questões da política nacional. A primeira propunha o envio de uma representação da assembléia provincial à 
16

Ver Diário do Rio de Janeiro, nº. 68 e 92, 1840.

17

Diário do Rio de Janeiro,, $\mathrm{n}^{\circ}-110,112,114$ \&t 116, 1840. Uma comissão especial foi eleita para considerar o projeto, tendo concluido que o projeto deveria ser abandonado pois propunha medida que escapava a alçada jurisdicional da assembléia provincial.

18

Diário do Rio de Janeiro, nº.94, 112 \& 116, 1840.

19

Ver também GOUVÊA, Maria de Fátima S. 0 império das provincias. Rio de Janeiro, 18221889. Rio de Janeiro: Civilização Brasileira/ FAPERJ, 2008. cap. III. assembléia legislativa nacional, exigindo a rápida suspensão do Ato de 1831, que havia suspendido o tráfico atlântico de escravos para o território brasileiro. 0 projeto não foi aprovado, sofrendo forte oposição principalmente de deputados com projeção política nacional. Estes argumentavam que 0 assunto não era da esfera de atuação da Assembléia e que esta deveria se manter dentro dos limites de sua jurisdição original. A matéria dizia respeito aos poderes decisórios do governo central e cabia a este tomar as decisões apropriadas sempre que conveniente ${ }^{16}$. No entanto, é sintomático observar que deputados provinciais como José Sousa Breves Filho e Monteiro de Barros se empenharam em favor na defesa da aprovação da proposta. Eram latifundiários, preocupados em assegurar o afluxo contínuo de escravos para a provincia a fim de manter o ritmo da produção agricola.

Mais tarde no mesmo ano, a assembléia provincial apresentou outra representação à assembléia geral. Dessa vez, propunha-se que o legislativo nacional antecipasse a declaração da maioridade política de D. Pedro II. Uma batalha política configurou a discussão dessa proposta. Seus opositores tentaram de todas as maneiras adiar a votação final, e quando esta finalmente aconteceu, asseguraram ter apoio suficiente para barrar a proposta ${ }^{17}$. Mais uma vez, as figuras de maior proeminência política na corte do Rio de Janeiro compareceram massiçamente a assembléia provincial com o objetivo de barrar o sucesso de tal proposta, sob a alegação de que ela era incompatível com as jurisdições da assembléia provincial definidas pelo Ato Institucional de1834.

Situação similar se verificou no debate sobre a concessão do subsídio a ser dado aos deputados provinciais que comparecessem as sessões da assembléia provincial fluminense. Isso incluía o pagamento de uma quantia em dinheiro pela presença em cada sessão diária e um auxilio adicional relativo às despesas com viagem. Até 1840 , não havia sido definido se os deputados provinciais receberiam qualquer auxilio por atenderem às sessões diárias. Cedo naquele ano, um grupo de deputados se opôs à medida com o argumento de que comparecer à assembléia provincial era a própria razão de ser da existência do deputado provincial e nenhum pagamento deveria ser feito para o cumprimento dessa obrigação básica. Políticos proeminentes na corte do Rio lideraram esse grupo. Enfatizavam a necessidade de estabelecer um senso de responsabilidade entre os deputados fluminenses acerca de suas posições enquanto membros da assembléia provincial. Outros deputados provinciais defendiam o argumento de que não era uma questão de compensação financeira, mas sim de sobrevivência dos deputados em uma cidade onde o custo de vida era superior aquele de onde haviam vindo originariamente. Santos Lobo, ligado ao Partido Liberal, argumentou que se opor à concessão de auxilio financeiro seria como estabelecer uma situação onde só os aristocratas poderiam despender seu tempo viajando até a capital para comparecer às sessões da assembléia. Isso, ele argumentou, poderia simplesmente aumentar a concentração do poder na província. Como resultado da crescente oposição, o projeto foi finalmente aprovado e um pagamento diário de $6 \$ 400$ réis foi dado a cada deputado fluminense que comparecesse à assembléia provincial18.

Outro importante debate aconteceu em relação a um projeto que tratava da organização da Tesouraria da Província ${ }^{19}$. 0 projeto teve o apoio do presidente da província Manuel José de Sousa França, que então enfrentava forte oposição na assembléia. 0 saquarema Paulino José Soares de Sousa, futuro Visconde do Uruguai, foi um forte opositor da proposta, 
20

GOUVÊA, Maria de Fátima S. 0 império das províncias. Rio de Janeiro, 1822-1889. Rio de Janeiro: Civilização Brasileira/FAPERJ, 2008.

Apesar da rejeição do projeto de Sousa França, uma reforma da administração das finanças provinciais foi realizada em 1842. Ela era, entretanto, muito diferente daquela discutida anteriormente. Centralizou o gerenciamento financeiro sobre um único órgão, mas manteve a ingerência do governo nacional na administração financeira da província, ao manter a Tesouraria da Província junto com o órgão recém-criado.

21

Não se sabe ao certo porque o Diário do Rio de Janeiro parou de publicar os debates da Assembléia fluminense depois da demissão de Sousa França. No curso dos debates pouco antes disso, se observou uma virulenta oposição a sua administração, liderada pelo deputado provincial João Manuel Pereira da Silva. Logo após, outro deputado provincial, o Visconde de Baependy, foi nomeado como vice-presidente da provincia. demonstrando preocupação em libertar a província do controle financeiro do governo central. Depois de intensos debates, o projeto foi rejeitado. Isso se deveu em parte a inovação organizacional suscitada pela proposta. Entretanto, o projeto era apoiado pelo presidente da província, um dos principais sustentáculos do Partido Liberal na província do Rio de Janeiro. A assembléia possuía uma maioria conservadora e disputas entre os dois grupos era constante. Logo após a rejeição do projeto, Sousa França foi dispensado do seu posto presidencial. Apesar disso, no ano seguinte um primeiro órgão administrativo das finanças públicas da província - a Administração da Fazenda da Província do Rio de Janeiro - foi criado pela presidência da província para cuidar de perto do gerenciamento das finanças provinciais 20 .

Por fim, uma última questão que vale ser aqui mencionada em relação à terceira magistratura fluminense foi o fato que, durante o período, uma lista de seis deputados foi escolhida dentre os membros da assembléia para compor uma lista de futuros vice-presidentes da província em caso de vacância do posto. Essa foi uma prática comum a partir de então na década de 1840. Dessa forma, os deputados provinciais se tornavam capazes de ocupar o posto de vice-presidente de província, como de fato aconteceu com os deputados Visconde de Baependy e Sousa França. Ambos eram líderes proeminentes dos partidos Conservador e Liberal na província, respectivamente. Uma maioria conservadora dentro da assembléia pode ser identificada na forte oposição ao então vice-presidente Sousa França, situação culminada com a sua demissão do cargo ${ }^{21}$.

No começo de março de 1842, a assembléia provincial inaugurou sua quarta legislatura. Várias reclamações foram feitas de início acerca da maneira como os debates estavam sendo publicados pelo Diário do Rio de Janeiro. Argumentava-se que isso era resultado da falta de pontualidade do editor e de sua pouca exatidão quanto à publicação dos informes da assembléia. 0 deputado João Alves Carneiro defendeu a necessidade de se proceder à mudança de editores, afirmando que o Correio Nycteroense seria uma escolha melhor, apesar de mais cara. No entanto, a discussão permaneceu em aberto em relação a possivel alteração do contrato. 0 nome de Luis Honório Vieira Souto surgiu do debate como uma solução para a melhora da qualidade da divulgação dos informes do legislativo provincial. Ele havia trabalhado como oficial da secretaria da assembléia e ia pouco a pouco se tornando em um dos mais conhecidos e proeminentes deputados em toda a história da assembléia provincial fluminense no século XIX. Estando bem informado acerca da rotina interna dos trabalhos da assembléia desde o início dos anos de 1840, ele foi capaz de fornecer um serviço editorial de alta qualidade, constituindo-se em elemento de ligação entre a assembléia e seus editores. Solução essa escolhida pelos deputados provinciais em 1842, confirmando assim a importância que o legislativo provincial devotava a sua imagem pública.

Nesse periodo, mais uma vez, a assembléia provincial fluminense parecia estar firmemente dominada por uma maioria dos deputados conservadores. Em várias ocasiões Sousa França parecia estar completamente sozinho, defendendo sua administração como vice-presidente em meio ao ataque massivo liderado pelos deputados Visconde de Baependy e Pereira da Silva. Essa maioria conservadora constituiu-se provavelmente na razão porque em 12 de março de 1842, um pedido de Francisco Cardoso foi tão subitamente aprovado. Ele havia proposto enviar uma representação provincial ao legislativo nacional. Seu objetivo era reafirmar o apoio 
22

Diário do Rio de Janeiro, n59, 1842. p.1.

23

Diário do Rio de Janeiro. Ver as sessões especiais em 12, 14 e 23 de abril. da província do Rio de Janeiro a decisão da Assembléia Geral em repudiar uma representação apresentada pela assembléia provincial de São Paulo em oposição ao Ato de 1841, que havia estabelecido a reforma do código de processo. A representação nutria a expectativa de conseguir sustar a reforma então em curso. 0 cenário de fundo se encontrava relacionado aos eventos que marcaram o final do movimento liberal de 1842. Souza França permaneceu na oposição mais uma vez 22 .

A reação ao discurso de Souza França foi enorme, e alguns deputados argumentaram que ele havia ofendido profundamente a integridade da assembléia provincial, ao qualificar seus membros de maneira tão baixa. No entanto, Souza França havia identificado com precisão a vulnerabilidade do legislativo provincial frente a forte pressão do governo central. Ele sabia que deputados provinciais como Joaquim José Rodrigues Torres, membro importante da liderança conservadora na assembléia, precisaria apenas exercitar parte de sua influência política para garantir a aprovação de qualquer proposta na assembléia.

Em 1842, outra importante representação da assembléia provincial foi aprovada. Fernando Sebastião Dias da Mota, importante membro ligado à cidade de Niterói na assembléia provincial, propôs que uma delegação composta por três deputados fosse constituída para apresentar "ao governo de Sua Majestade" os respeitos da assembléia em apoio a sua ação contra o governo britânico. De acordo com os debates da assembléia provincial, a Inglaterra havia pago ao Jornal do Commercio para publicar um artigo na edição de 08 de abril de 1842, artigo esse em que o governo brasileiro fora ameaçado com uma retaliação britânica caso o acordo econômico de 1831, no qual o Brasil havia concordado em abolir o tráfico de escravos no Atlântico, não fosse renovado. Os deputados provinciais fluminenses, dizia Dias da Mota, tinham o dever de mostrar o seu total compromisso em defender a integridade do Brasil como uma nação independente. A despeito da oposição de alguns deputados, sob o pretexto de que o conteúdo da proposta era estranho às jurisdições da assembléia provincial, a maioria dos deputados se mostrou mais preocupada em defender o livre fluxo de escravos para o país 23 .

No ano de 1843, o debate esteve firmemente concentrado a três principais questões. A primeira foi um projeto apoiado pelo deputado conservador João Nepomuceno Castrioto, que propunha a expropriação do canal de Itaguaí. 0 deputado Bernardo Augusto Nascentes de Azambuja opôs-se firmemente ao projeto, argumentando que o proprietário ainda estava ligado ao governo provincial por acordo que o obrigava a operar o canal por mais 20 anos, em troca da concessão da construção do canal. A oposição foi forte, indicando uma mudança no equilíbrio político dentro da assembléia. Isso se deveu, principalmente, a ausência de um grande número de deputados, que haviam deixado a assembléia provincial para atender a sessão anual da Assembléia Geral.

Entretanto, o próprio beneficiado com a concessão do canal de Itaguaí em pessoa, Francisco José Cardoso, era membro da assembléia provincial nessa legislatura. Este foi também o primeiro de uma série de debates envolvendo o nome da família Cardoso em referência a expropriação de projetos de obras públicas que haviam tomado sob patrocínio do governo provincial. Apesar de Cardoso ter ficado aparentemente calado durante todo o debate, foram constantes as referências ao fato de ser ele parte interessada na discussão. 0 projeto não foi aprovado como Castrioto o 
24

Prática que em grande medida remonta a experiência observada anteriormente no Brasil colonial de arrendamento de contratos como expediente da gestão administrativa, particularmente a fiscal, ver: FRAGOSO, J.; GOUVÊA, M. F. S.; BICALHO, M. F. B.. Uma leitura do Brasil colonial. Bases da materialidade e da governabilidade no Império. Penélope. Lisboa, 23, 2000. p.67-88.

25

Ver Diário do Rio de Janeiro, nº. 93, 1843.

Diário do Rio de Janeiro, n. 92, 93, 95, 97, 102, 105, 108 \& 111, 1843.

havia apresentado inicialmente. A emenda de Azambuja foi aprovada, estabelecendo que o canal só poderia ser expropriado depois de passados os 20 anos do estabelecimento do acordo.

Pessoas como o deputado Francisco José Cardoso freqüentemente conseguiam ter forte apoio na Assembléia Provincial quando procuravam obter recompensas por terem assumido a realização de obras públicas na província. Tendo sido a obra concluída, os investidores iniciavam contatos com seus associados no interior da assembléia sob o argumento de que haviam cumprido sua parte no contrato a despeito dos enormes prejuízos, cabendo então ao legislativo provincial considerar a necessidade de quebra de contrato em face dos altos custos não previstos inicialmente 24 .

Em uma última grande observada nos debates de 1843 encontram-se questões relacionadas à revolta liberal de 1842 . Os debates da assembléia provincial, como a maioria da documentação oficial fluminense produzida no século XIX, consideraram o movimento como algo completamente estranho a província fluminense. No entanto, o debate falha em convencer o leitor mais atento acerca das especulações referentes aos acontecimentos no municipio de Paraiba do Sul. 0 deputado Siqueira chegou a dizer que não havia documentos oficiais que pudessem comprovar a veracidade dos acontecimentos naquele município 25. Toda a questão surgiu por causa da proposta de constituição de uma delegação da assembléia provincial que o deputado Dias da Mota queria enviar para a Assembléia Nacional. A representação tinha como propósito pedir o perdão para todos aqueles que haviam participado da revolta de 1842. Ele argumentava que era necessário limpar o movimento da história do Brasil e que isso só seria possivel através do pleno perdão de todos os envolvidos. Ninguém mais teria uma ficha criminal e a situação política poderia retornar aquela de antes da revolta. Uma comissão especial foi então eleita para fazer uma análise da proposta. 0 veredicto foi contrário com a alegação de que não cabia a assembléia provincial propor tal medida.

Discussões acaloradas se seguiram. 0 argumento básico em apoio a proposta de Dias da Mota era de que o governo central era tão responsável pela rebelião quanto aqueles que se armaram contra o governo. A maneira como o governo havia aprovado a reforma do Código de Processo, assim como também o modo como as eleições haviam sido manipuladas pelo mesmo governo, não deixaram outra alternativa àqueles que tanto se opuseram às reformas que não fosse a rebelião, argumentou Dias da Mota. A oposição não conseguiu derrubar tal argumento, afirmando apenas que aquela não era uma matéria de jurisdição da assembléia provincial. Uma feroz confrontação desenvolveu-se entre Dias da Mota e os membros da comissão especial: deputados Siqueira, Inácio Francisco Silveira da Mota e João Alves Loureiro. Dias da Mota era apoiado pelos deputados José Cristino da Costa Cabral, Tomas Gomes dos Santos, João Silveira do Pilar, José Augusto César de Meneses, Deocleciano Augusto César do Amaral e Josino do Nascimento Silva, entre outros. Os deputados Azambuja e Alves Carneiro, apesar de serem membros da comissão especial, assumiram posições ambivalentes. Sousa França apoiou a decisão da comissão contra a proposta de Dias da Mota. A votação final sobre a matéria aconteceu em 13 de maio de 1843. Surpreendentemente, apenas um deputado votou contra a proposta de Dias da Mota, provando que no fundo esta tinha o amplo apoio de todos os grupos da assembléia 26 . 
Apenas informações espaçadas se encontram disponiveis para consulta no Jornal do Commercio.

\section{8}

Ver GOUVÊA, Maria de Fátima S. 0 império das provincias. Rio de Janeiro, 1822-1889. Rio de Janeiro: Civilização Brasileira/FAPERJ, 2008. cap. II.

29

Em 09 de abril, a assembléia provincial recebeu um comunicado oficial do vice-presidente de provincia Candido Batista de Oliveira adiando a sessão anual da Assembléia para 06 de junho de 1845. Ver Jornal do Commercio, n. 95, 1845.

30

Francisco José Cardoso era, novamente, membro da assembléia fluminense.

31

Diário do Rio de Janeiro, no. 7460-7465 e 7489, 1847.

\section{2}

Outras reformas discutidas durante esse periodo diziam respeito ao sistema educacional e a administração de obras públicas na província.

33

Aureliano de Sousa e Oliveira Coutinho, depois Visconde de Sepetiba, foi presidente da provincia até 3 de abril de 1848, quando foi substituído por Manuel de Jesus Valderato, depois Visconde de Valderato. É interessante notar que Valderato permaneceu no cargo por apenas dois meses, quando foi prontamente substituído por Felisberto Caldeira Brant Pontes, depois Visconde de Barbacena. Ver: Diário do Rio de Janeiro, n. 7773, 1848. Ver também: LACOMBE, Lourenço Luis. Os chefes do executivo fluminense. Petrópolis: Vozes, 1973.
Pouco pode ser encontrado acerca da legislatura seguinte (18441845), sendo que a maior parte dos debates não foi publicada27. Há fortes indicações que em 1844 houve um grande debate em torno de propostas de melhorias técnicas na produção de açúcar na província. Em 1845 longas discussões foram realizadas em torno da reforma administrativa da província que acabaram culminando na autorização do presidente de província em fazer ele mesmo as alterações necessárias em relação à matéria. Atenção especial foi dada à maneira como o gerenciamento das obras públicas vinham sendo realizadas na província. Outra reforma foi realizada na Tesouraria Provincial em junho de 1846, como apontado 28. Novos indícios de enfrentamento foram observados entre a assembléia fluminense e a presidência da província. 0 Jornal do Commercio informou que a assembléia provincial havia sido adiada para junho de 1845 , bem como o deputado João Alves Loureiro foi demitido da secretaria de finanças públicas (nas duas administrações, nacional e provincial) 29.

Durante a sexta legislatura (1846-1847), a ausência de políticos importantes no cenário da grande política no interior da assembléia provincial criou aparentemente um vácuo político na liderança da assembléia. As várias facções estavam aparentemente divididas de maneira menos conflituosa. Em 1847, a freqüência dos deputados provinciais nas sessões da assembléia atingiu um dos seus pontos mais baixos. A necessidade de convocar deputados substitutos fazia-se cada vez maior. Deputados ausentes das primeiras 15 sessões diárias da assembléia, sem autorização prévia, eram automaticamente substituídos. Logo após, um afluxo mais contínuo de deputados passou a comparecer a assembléia. Os deputados Dias da Mota e Gomes de Meneses lideraram os dois principais grupos politicos. A maior parte dos debates concentrou-se em duas principais questões. Uma nova tentativa de propor recompensar financeiramente Francisco José Cardoso pela quebra da concessão de manutenção do canal de Itaguaí, tentativa que desta vez teve sucesso, a despeito da falta de consenso acerca da quantia a ser paga pela província ao readquirir o controle do canal 30 .

Uma segunda proposta debatida foi o estabelecimento de um banco provincial em auxílio à agricultura fluminense ${ }^{31}$. 0 objetivo inicial era criar uma instituição financeira que pudesse facilitar o acesso ao crédito por parte dos fazendeiros na província. Os deputados Sousa França e Pedro Ramos Silva concordaram que a melhor maneira de proceder com a matéria seria através da redução das taxas de juros nas transações financeiras. Também foram a concessão de prazos mais longos de pagamento e de novos termos de segurança que poderiam aumentar o número de fazendeiros capazes de se beneficiar do futuro banco. Discussões sobre a organização do banco, bem como do tipo de vínculo que deve ligá-lo à administração provincial foram exaustivas. 0 deputado João Pereira da Costa Mota teve cuidado especial em defender a idéia de que estrangeiros poderiam ocupar lugar nos altos escalões da direção do banco. No entanto, a maioria dos deputados se opôs à proposta, que foi finalmente rejeitada 32 .

Em seguida, a sétima legislatura (1848-1849) foi marcada por uma ampla gama de debates de natureza distinta daqueles observados nos períodos anteriores. Desde o começo, um claro conflito estabeleceu-se entre as duas principais facções presentes na assembléia. Situação essa causada em parte pela expressão da forte oposição da maioria dos deputados provinciais ao presidente da província ${ }^{33}$. Esse conflito acabou concorrendo para uma situação sem precedentes, na qual a assembléia provincial fluminense 
34

Ver Diário do Rio de Janeiro, nº. 7846, 1848.

35

Diário do Rio de Janeiro.

36

Ver este detalhado e cuidadosamente preparado discurso de 09 de agosto, no Diário do Rio de Janeiro, no. 7868 e 7869, 1848. Ele seguiu a mesma linha defendida pelo Visconde de Baependy na véspera, defendendo que a única maneira de reduzir o déficit provincial seria através da redução de investimentos em obras públicas. Ele também argumentava que não era dever do governo provincial estabelecer um sistema de letras de dividas. Este era um mecanismo poderoso e perigoso que deveria ser usado somente pelo governo nacional.

37

É interessante notar que apesar de ser contrário à medida, o Visconde de Baependy não pode votar com a oposição na votação final. A questão parece ter evoluido para um teste de confiança do lado mais importante da Assembléia na Presidência da Província. Logo, podemos argumentar que Baependy não poderia deixar de alinhar-se com seus colegas de partidos apoiando o presidente provincial Visconde de Barbacena. trabalhou em sessões preparatórias por quase dois meses. 0 presidente da assembléia provincial defendeu o direito do legislativo fluminense de examinar as eleições, enquanto a comissão que deveria tratar da matéria defendeu a necessidade de aguardar o reconhecimento emitido pela Assembléia Nacional. 0 presidente argumentou que a assembléia tinha o direito soberano de decidir se suas eleições deveriam ser reconhecidas ou não, sendo que a comissão defendeu fortemente que esta prerrogativa pertencia a Assembléia Nacional. Linhas bem definidas foram traçadas contra e a favor da presidência da província, que não esperou por tal reconhecimento. Foi apenas no final de maio de 1848 que as duas partes chegaram a um compromisso, possibilitando assim a abertura formal da 7. ${ }^{\text {a }}$ legislatura. Isso foi viabilizado pela alteração da comissão, tendo um de seus membros sido substituído pelo deputado Azambuja.

Assim que a sessão ordinária do legislativo provincial foi formalmente inaugurada, novas tensões políticas foram observadas no interior da assembléia. Durante esse mesmo ano, os deputados provinciais também debateram as acusações da Assembléia Nacional de que a assembléia provincial fluminense tinha dentre os seus membros dois portugueses. 0 assunto surgiu na Assembléia Geral em termos da definição de uma política de combate a influência estrangeira em assuntos internos ${ }^{34}$. A assembléia provincial fluminense foi rápida em divulgar uma declaração rejeitando tais acusações, que provavelmente visavam atingir os deputados provinciais Francisco José Cardoso e Lourenço Vieira de Sousa Meirelles. É possivel argumentar que a disputa por trás da matéria era a oposição à compensação financeira a ser paga ao deputado Cardoso em razão da expropriação do canal de Itaguaí35.

Outro importante assunto discutido em 1846 foi se província estaria ou não enfrentando uma situação de déficit financeiro. Temia-se que as revoluções de 1848 pudessem afetar o consumo europeu de gêneros alimentícios brasileiros. Juntamente com a proposta do presidente da província de se criar letras de dívida da província, a matéria constituiu-se na base sobre a qual foram realizados longos debates sobre a verdadeira situação financeira da província do Rio de Janeiro. Montezuma defendeu o argumento de que se as letras de dívida da provincia fossem criadas, a crescente crise financeira não seria resolvida, já que se formalizaria uma situação de déficit na província. Dessa forma, o governo provincial estava apenas propondo um sistema no qual o déficit seria tomado como algo dado e perdido e os gastos continuariam sendo feitos como sempre, disfarçados pelo novo sistema ${ }^{36}$. Muitos deputados concordaram com essa posição. Entretanto, a presidência da província foi capaz de reunir um número suficiente de deputados na assembléia, conseguindo assim a aprovação da proposta ${ }^{37}$.

A reforma do regimento interno da assembléia provincial foi também discutida nesse mesmo ano. 0 Visconde de Baependy defendeu a necessidade de alterar a data de início das sessões anuais. Ele e outros deputados argumentaram que isto era necessário na medida em que os fazendeiros não teriam como freqüentar a assembléia provincial e ao mesmo cuidar de suas propriedades durante o periodo de colheita. Outras modificações foram aprovadas, de maneira que o regimento interno pudesse atender também as modificações determinadas pela legislação eleitoral editada em 1846. Dessa forma, a assembléia fluminense assistiu a ampliação de suas atribuições em termos da verificação dos diplomas eleitorais de seus 
38

Belarmino Ricardo Siqueira, Dias da Mota, Francisco Cardoso, Manuel Joaquim da Silva, Hermenegildo da Cunha Ribeiro Feijó, Antonio Henriques de Miranda Rego, Francisco Paula Monteiro de Barros, Joaquim Bandeira de Gouvêa e Antonio Álvares de Miranda Varejão. Ver Diário do Rio de Janeiro, nº. 7853, 1848. p. 1.

\section{9}

Diário do Rio de Janeiro, n. 7853, 1848. p. 2. Joaquim José de Sousa Breves era um dos mais proeminentes líderes do Partido Liberal no interior da província fluminense. Ele esteve diretamente envolvido na revolta de 1842 , tendo sido o líder do movimento na província. Ver ATHAYDE, José Botelho. Joaquim José de Sousa Breves - biografia, Rio de Janeiro, IHGB. (mimeo). p. 08.

40

Diário do Rio de Janeiro, nº. 7856, 1848. p. 2.

41

Os primeiros três municípios foram criados nas décadas de 1830 e 1840. Rio Claro foi criado posteriormente. Deve-se ter em conta também a forma pela qual o formato das freguesias era redefinido durante o periodo, fato que alterava também as forças policiais dos municipios de acordo. No entanto, deve-se mencionar o apoio de Baependy às reivindicações de Breves. Ele pode ter concluído que continuar com a reorganização de municípios na região poderia comprometer toda a estratégia conservadora de estabilização política na região.

42

Ver Diário do Rio de Janeiro, nº.7857, 1848. p. 1. próprios membros, tendo que apenas se render ao aval da Assembléia Nacional em relação a assuntos isolados.

Disputas entre grupos locais ocuparam boa parte do debate político verificado nessa legislatura. Um conjunto de deputados provinciais apresentou um projeto que transferia parte das terras de Diogo Teixeira de Macedo do município de São João do Príncipe para o de Barra do Pirai38. 0 deputado Joaquim de Sousa Breve, o então presidente da Câmara de Barra do Pirai, liderou a oposição ao projeto. Ele argumentou que a medida iria produzir uma representação desproporcional do partido oligárquico em seu município e argumentou que durante o período em que o Partido Conservador esteve no poder, a região mostrou-se muito instável politicamente. Falando como uma espécie de defensor do partido, Diogo Macedo não tinha as mesmas reservas que Breves que, se a situação em Piraí revertesse, não teria alternativa a não ser se retirar dada a grande instabilidade que passaria então a prevalecer na região novamente ${ }^{39}$. De uma perspectiva diferente, o Visconde de Baependy acreditava que São João do Príncipe estava sendo alvo de um tipo de discriminação, já que seu território vinha sendo constantemente sub-dividido. Processo esse que havia sido iniciado com a organização dos municípios de Valença, Barra Mansa e Piraí. Em outra ocasião, outra parte do município foi cedida a Rio Claro. 0 Visconde sentia que seria melhor dissolver o município de uma só vez do que continuar a agir dessa forma ${ }^{40}$. Ele foi o único deputado que apoiou Breves. Um projeto substituto foi apresentado por Francisco Cardoso, projeto esse que foi finalmente aprovado apesar da intensa oposição de Breves. Questão essa deveras relevante à luz dos acontecimentos de 1842. Os municípios mais a oeste da província do Rio de Janeiro haviam se constituído em palco de intensos conflitos em 1842 - seja entre as autoridades da corte do Rio de Janeiro e as forças rebeldes de Minas Gerais e São Paulo, seja entre os grupos rebeldes do Rio de Janeiro e o governo provincial. É muito provável que o processo de reorganização das estruturas municipais estivesse relacionado a intenção de reforçar a presença conservadora como forma de contrabalançar a forte influência liberal na região ${ }^{41}$.

Durante essa legislatura, a assembléia fluminense novamente deu sua aprovação para o envio de mais uma representação a Corte do Rio de Janeiro. 0 deputado Montezuma propôs a moção de que a assembléia provincial demonstrasse publicamente o seu apoio a D. Pedro II em resposta aos movimentos anti-monárquicos em curso na Europa. Ele argumentou que estava em jogo a segurança das princesas brasileiras casadas com nobres europeus que viviam na Europa. Ele defendia que a assembléia deveria oferecer seu apoio e garantir as Suas Majestades que "o Brasil era o refúgio mais seguro para todos os membros da família real"42. Os deputados Castrioto e Dias da Mota se opuseram a proposta em face de sua obviedade. No entanto, a moção foi rapidamente aprovada, e um grupo de 13 deputados fluminenses foi escolhido para expressar os sentimentos da assembléia provincial ao imperador. Podemos argumentar que o verdadeiro propósito por trás dessa questão era reforçar o compromisso da província fluminense em apoiar o sistema monárquico no país. Isto era particularmente relevante durante um período no qual se começava a temer os distúrbios em curso no nordeste do Brasil, situação acentuada pela preocupação de que os eventos observados na Europa pudessem causar distúrbios ainda mais sérios no país. 
43

No entanto, o deputado Visconde de Baependy argumentou que esta não era a única solução para o problema. De fato, ele acreditava que seria mais inteligente promover a instituição de uma estrutura mais profissional no processo de seleção para preencher os postos de autoridade na polícia local. Ver Diário do Rio de Janeiro, ${ }^{\circ}$. 7853, 1848.

\section{4}

Estranhamente, não há nenhuma indicação do que estava de fato acontecendo para fundamentar tanta preocupação. Os deputados provinciais apenas mencionaram pequenos acontecimentos. Eles basicamente temiam a possibilidade de eventos similares aos que aconteciam em Pernambuco desde junho daquele ano e que iriam culminar posteriormente na Revolta da Praieira.

45

Ver Diário do Rio de Janeiro, nº. 7842, 1848

\section{6}

Esse tipo de reivindicação passou a aparecer com maior freqüência na assembléia provincial, indicando a complexidade dos laços que ligavam a provincia do Rio de Janeiro ao governo central.
Uma outra questão relacionada a isso pode ser observada na preocupação de alguns deputados provinciais em preparar o projeto do contingente da força policial da província. 0 debate centrou-se em duas principais questões. Primeiro, o medo expresso pela maioria dos deputados de que a ordem pública estava ameaçada na província. Apesar de imprecisos na identificação das bases para tal medo, eles freqüentemente referiam-se a "algo acontecido em Iguassú", onde "forças rebeldes" conseguiram desmantelar a barreira alfandegária local. Isso ocorreu apesar do governo provincial ter enviado policiamento adicional para a área, temendo que tal fato acontecesse. Os deputados criticaram a facilidade com que qualquer comunidade poderia contra as determinações da administração provincial.

A segunda questão derivava em grande medida da primeira. Se a ordem pública estava comprometida, o número de policiais disponiveis na província deveria ser ampliado urgentemente ${ }^{43}$. Uma comissão especial foi composta na assembléia para estudar a validade de se criar 180 novos postos militares na província. 0 pânico alcançou tamanho nível de incidência que até mesmo uma sessão secreta da assembléia foi convocada para discutir o assunto 44 . Mais a frente, no curso da sessão ordinária anual, a maior parte dos deputados provinciais acabaram concordando que a situação, como por eles denominado, havia se acalmado. Aparentemente, não havia necessidade para se enfrentar o encargo financeiro que a ampliação da força policial acarretaria para a província. Caso surgisse alguma situação de emergência inesperada, a administração provincial deveria capaz de conter a situação através do pedido de forças adicionais ao governo nacional.

Essa decisão indicava uma nova tendência política na assembléia provincial. Alguns deputados começavam a mostrar sua insatisfação com a maneira como o governo da corte do Rio de Janeiro vinha respondendo as necessidades da província fluminense. Os deputados provinciais Azambuja e Ângelo Tomas do Amaral defenderam com muita firmeza a necessidade de se encaminhar uma representação à Assembléia Nacional, na qual a assembléia fluminense pudesse expressar seu sentimento e pedir apoio adicional do governo central para realização de algumas obras públicas. 0 deputado José Araújo Coutinho também apoiou essa posição. Esse grupo acreditava que a província do Rio de Janeiro "não estava recebendo o mesmo tipo de tratamento que estava sendo dado a outras províncias no país" 45. Argumentavam que se alguma província deveria ser apoiada financeiramente pelo governo central, esta deveria ser a província do Rio de Janeiro já que esta era a que mais contribuía para o crescimento da renda do país como um todo 46 .

Os debates na assembléia provincial no ano de 1849 foram marcados inicialmente pela repercussão das medidas tomadas pelo governo central em Pernambuco para suprimir a revolta da Praieira. Divisões surgiram no interior dos partidos políticos. 0 grupo liberal encarou um dilema difícil. Deputados liberais, como Dias da Mota, diziam que nenhum apoio deveria ser dado àqueles que pegaram em armas contra o governo central. Apesar de todos os motivos válidos para assim agir, os envolvidos na revolta Praieira deveriam ser duramente criticados por terem optado pela luta armada. 0 deputado Francisco de Sales Torres Homem, futuro Visconde de Inhorim, liderou o outro grupo liberal, que acusava o governo central de ser tão culpado pela revolta quanto as forças rebeldes. Apesar de não 
47

Ver Diário do Rio de Janeiro, nº. 8036, 1848.

\section{8}

Ver também discursos posteriores do deputado liberal Tomas Gomes dos Santos, nos quais ele claramente culpou o partido Saquarema, como ele colocava, por instigar distúrbios políticos dentro da província do Rio de Janeiro, assim como também em Pernambuco, ver Diário do Rio de Janeiro, nº. 8053, 1849. p. 2 e 3.

49

Diário do Rio de Janeiro, nº. 8042, 1849. Ver também o discurso de Alves Carneiro em 23 de abril, no qual diz que "o Império do Brasil está na Corte e não na soma das províncias, e a Corte nas mãos dos ministros, está é a maior causa de nossos males", Diário do Rio de janeiro, n. 8083, 1849. As duas declarações indicam a percepção que a assembléia tinha das limitações que verificadas no império do Brasil. Se por um lado, o sistema político estava sendo imposto pelo centro às áreas circundantes, por outro, as divisões dentro dos grupos dominantes davam brecha para o surgimento de conflitos, como os de 1842 e 1848.

50

Dias da Mota se alinhou com esse grupo, pois apesar de liberal, opunha-se a luta armada. assumir uma posição determinada em relação a escolha dos rebeldes pela luta armada, este grupo preferiu manter o foco da discussão na critica ao governo central como provocador desse tipo de reação.

Assim que foi aberta a sessão ordinária da assembléia, Torres Homem apresentou um pedido de informação ao governo provincial se era verdade a informação de que membros do Partido Liberal estavam sendo deliberadamente perseguidos na província do Rio de Janeiro 47 . Ele estava preocupado com a omissão do governo provincial em proteger os liberais das agressões não-justificadas de muitas autoridades. Ele analisou ainda a maneira como os que apoiaram os liberais estavam sendo tratados após a supressão da revolta de Pernambuco. Temia que a tendência em identificar adeptos liberais como sendo também adeptos da luta armada, situação que poderia causar sérios danos à estabilidade política do país. Pior ainda era o precedente estabelecido pelo governo central ao fechar a Assembléia Nacional por 15 meses. Isto era totalmente contrário à constituição política do país. A gravidade da situação foi considerada como sendo o resultado da crescente insatisfação do país com a maneira como os saquaremas vinham exercendo total controle sobre o gerenciamento político do país ${ }^{48}$. Passou então a criticar tanto o governo central, quanto o de Pernambuco, dizendo que "o poder já fora absoluto no centro, mas fragmentado no campo, enquanto que agora está fragmentado no centro e limitado na periferia" 49.

Esta declaração levou a maior parte dos deputados a defender o fato de que o governo central, e a presidência da província de Pernambuco em particular, agisse de modo conciliador em relação à revolta liberal. 0 debate foi longo e intenso, ocupando a maior parte do tempo das sessões que se seguiram. De um lado, os deputados Barão de Lages, José da Cunha Barbosa, Dias da Mota, Azambuja, Emiliano Fagundes Varela e Rafael Pereira de Carvalho50, firmes na defesa das ações tomadas contra os liberais de Pernambuco. Do outro, Manuel Joaquim da Silva, Torres Homem, Gomes Meneses, Tomas Gomes dos Santos e Alves Branco, criticaram as ações dos governos provincial e central contra os partidários liberais como um todo. 0 impasse entre os dois lados era insolúvel. Chegou-se a um acordo com a decisão de se encaminhar a matéria a uma comissão especial da assembléia provincial, composta pelos deputados Azambuja, Dias da Mota e Bernardes da Gouvêa. Em um movimento estratégico, a decisão da comissão sobre o assunto só foi divulgada no último dia da sessão ordinária anual da assembléia. Como esperado, sua proposta era contrária ao pedido de informações ao governo provincial de Torres Homem. Apesar de não ter conseguido forçar a assembléia provincial a condenar formalmente as ações do governo central, os membros mais radicais do Partido Liberal presentes na assembléia foram muito bem sucedidos em expressar seus pontos de vista sobre as mazelas que vicejavam o sistema político imperial. Mais ainda, eles foram extremamente hábeis em utilizar o espaço do legislativo como canal de expressão de seus pontos de vista. Isto demonstra de modo bastante expressivo a forma como a assembléia provincial servia de arena para expressão política dos diversos grupos existentes no país, particularmente em um periodo em que a Assembléia Nacional não estava disponivel para a explicitação dos diversos protestos políticos.

A maneira como a presidência provincial tratou o projeto do orçamento provincial também serviu de alvo para muitas críticas. Em meio a debates conflitantes sobre o projeto, o deputado Gomes Meneses argu- 
51

Ver Diário do Rio de Janeiro, nº. 8069, 1849. Essa foi a primeira vez que se levantou esse argumento dentro da assembléia provincial fluminense. Entretanto, ele seria mais tarde usado com grande freqüência, se constituindo em uma das mais importantes ferramentas de expressão da oposição da assembléia provincial à presidência da província.

52

Ver GOUVÊA, Maria de Fátima S. 0 império das províncias. Rio de Janeiro, 1822-1889. Rio de Janeiro: Civilização Brasileira/FAPERJ, 2008. caps. IV, V e VI. mentou que todo o esforço que a assembléia dedicava a essa discussão era sem sentido na medida em que a presidência da província nunca dava atenção àquilo que a assembléia determinava a cada ano. Da mesma forma, ele argumentou que o legislativo provincial nunca havia se preocupado em reclamar ou censurar a presidência da província por agir dessa maneira51.

0 final da década de 1840 foi marcado pelos debates na assembléia provincial que buscavam estabelecer uma nova linha de argumentação em termos de seus conteúdos e de sua organização. Diferiam dramaticamente daqueles observados na década anterior. Houve uma maior ênfase na adoção de um estilo mais profissional e, por assim dizer, "empresarial" por parte da assembléia. Ao mesmo tempo, um programa mais claramente definido, baseado em assuntos exclusivamente fluminenses, tornou-se a preocupação central da maioria dos deputados. Depois dos primeiros anos, período em que os deputados se encontravam mais preocupado com a definição dos poderes e jurisdições da assembléia provincial do que em efetivamente utilizá-los, abria-se, enfim, um novo período em que a assembléia parecia se sentir pronta para trilhar um novo caminho político52.

\section{Conclusão}

Um dos principais argumentos aqui desenvolvido é o de que a despeito do império do Brasil ter se constituido em um sistema político-administrativo altamente centralizado - a monarquia constitucional brasileira -, a dinâmica política provincial desempenhou um papel muito mais preponderante daquele que lhe é usualmente atribuido em termos do sistema político como um todo. A política provincial era algo marcado por intenso debate e forte disputa, contexto em que a barganha de poderes se constituia em elemento fundamental na implementação da maioria das estratégias políticas então articuladas.

No caso da provincia do Rio de Janeiro, um significativo grande número de assuntos foi rotineiramente discutido, diversos interesses econômicos foram acomodados, bem como politicas e estratégias foram definidas e aplicadas na província como um todo. No coração da política provincial do Rio de Janeiro se encontrava situada a assembléia legislativa provincial. 0 papel desempenhado pelos deputados provinciais foi, portanto, crucial. Eles atuaram no sentido de considerar, apoiar, formalizar e implementar várias medidas incluindo, inclusive, um programa de defesa das estruturas do setor agro-exportador da província.

Este programa foi principalmente englobado por três grupos principais de políticas implementadas no âmbito provincial a partir dos anos de 1850. 0 primeiro, e mais importante, foi baseado na organização de um sistema de transportes na província do Rio de Janeiro. Uma segunda linha de ação política foi desenvolvida pelos deputados provinciais em relação a substituição do "elemento servil" pela mão-de-obra livre. Uma terceira e última linha de estratégia política foi adotada pelos deputados da assembléia provincial fluminense em relação aos meios possiveis de se promover uma diversificação econômica em favor da produção de produtos para além do café na província.

Além disso, vale também lembrar o fato de que a assembléia provincial era ela mesma uma instituição definida pela legislação do governo central como o principal fórum político a nivel provincial no sistema político do Brasil no século XIX. Situação essa definida pelo fato de que a assembléia provincial era encarregada de organizar e aprovar os orçamentos municipais 
e o orçamento provincial anual, jurisdição que revestia essa instituição com poderes em acomodar e ajustar uma gama bastante ampla de interesses econômicos prevalecentes na província, assim como também no governo geral na pessoa do presidente de província. Deve ser também observado que, no interior da assembléia provincial, alguns deputados se destacaram dos demais por sua capacidade em viabilizar o positivo curso dos debates e da aprovação da legislação provincial a ser editada por esse órgão.

Isso tornou possível a constituição de um conjunto de estratégias de sobrevivência de diversos grupos locais/ regionais frente às adversidades econômicas enfrentadas na província, especialmente a partir da década de 1850. Fato esse que conferiu à assembléia provincial do Rio de Janeiro um papel preponderante em termos da institucionalização - a médio e longo prazo - de estratégias de ação política instituídas pelos grupos dominantes presentes na província como um todo. Com o passar do tempo, lideranças politicas oriundas da província foram pouco a pouco se retirando da grande cena política do país, restringindo sua atuação ao cenário político provincial, a exemplo do que havia feito o Conselheiro Paulino. Ao longo do período, os políticos fluminenses puderam desse modo concentrar suas ações em favor da preservação das estruturas de poder já então existentes na provincia.

Recebido para publicação em março de 2008

Aprovado em abril de 2008 